\title{
MOTOR DEVELOPMENT IN THE HOSPITALIZED INFANT AND ITS BIOLOGICAL AND
} ENVIRONMENTAL CHARACTERISTICS

Clin Biomed Res. 2018;38(1):66-73

1 Curso de Fisioterapia, Escola de Saúde, Universidade do Vale do Rio dos Sinos (Unisinos). São Leopoldo, RS, Brasil.

2 Escola de Saúde, Universidade do Vale do Rio dos Sinos (Unisinos). São Leopoldo, RS, Brasil.

3 Programa de Pós-Graduação em Ciências do Movimento Humano, Universidade Federal do Rio Grande do Sul (UFRGS). Porto Alegre, RS, Brasil.

4 Universidade Regional do Cariri (URCA). Crato, CE, Brasil.

Corresponding author:

Alessandra Bombarda Müller abombarda@unisinos.br

Programa de Pós-Graduação em Ciências do Movimento Humano, Universidade Federal do Rio Grande do Sul (UFRGS). Rua Felizardo, 750. 90690-200, Porto Alegre, RS, Brasil.

\author{
Eunice Cristina Pufal ${ }^{1}$, Alessandra Bombarda Müller ${ }^{2,3}$, \\ Paulo Felipe Ribeiro Bandeira ${ }^{3,4}$, Nadia Cristina Valentini ${ }^{3}$
}

\begin{abstract}
Introduction: Hospitalization is a risk factor for delayed motor development, due to the lack of adequate stimulation; therefore, it is important to assess child development during hospital admission.
\end{abstract}

Methods: In this study, motor development of previously healthy hospitalized infants was assessed and associated with biological and environmental characteristics, including length of hospital stay and physiotherapeutic treatment. The assessment was made before discharge, with questionnaires and a motor assessment scale.

Results: The sample of 32 infants aged from zero to 18 months had an average length of hospital stay of $4.94 \pm 2.39$ days. $50 \%$ of infants were girls $(n=16)$ and mostly belonged to socioeconomic class $C(n=16)$. Length of hospital stay explained only $3.3 \%$ of motor development variation, showing no significant impact. Infants from lower socioeconomic classes were nearly six times more susceptible to motor delays than those belonging to higher classes $(p=0.05)$. During hospitalization, $25 \%$ of the sample $(n=8)$ was treated with physiotherapy. All these patients were hospitalized for respiratory dysfunction and presented five times less chance of altered motor development when compared to those who did not undergo physiotherapy.

Conclusion: These results should be interpreted with caution, since the type of physiotherapy care provided and infant's degree of motor impairment were unknown. In this study, length of stay and hospital environment were not significant risk factors when analyzed individually, concluding that the greater the exposure and the amount of associated factors, the more susceptible the infant will be to present motor delays.

Keywords: Child development; hospitalization; developmental disabilities

The early years of life are considered a critical period in childhood learning because the nervous system optimizes neural connections during this period and promotes development in its various dimensions sequentially and continuously ${ }^{1,2}$. This progress takes place from conception and advances in a maturative form, allowing interactions with external stimuli ${ }^{3}$. The constant behavioral adaptation over time is stimulated by the interaction between children's needs, their biological formation, and factors provided by the environment in which they are inserted ${ }^{4}$.

Child's meaning of things is constructed by the organization of sensory experiences and movement: children learn and develop through their physical interaction with the environment ${ }^{4}$. At birth, this interaction occurs through reflexive, involuntary movements, associated with the acquisition of the antigravity posture and the manipulation of objects. With the child's adaptation to the environment, the rudimentary voluntary movement will favor stabilizing skills, such as cephalic control; locomotive skills, such as crawling and walking; and manipulative skills, such as reaching, grasping and releasing ${ }^{5}$.

Child development is influenced by biological and environmental factors that may favor or compromise this process ${ }^{6}$. Risk factors that increase the probability of developmental deficits include: early gestational age, low birth 
weight, use of mechanical ventilation, inadequate income and family structure, and lack of a stimulating environment ${ }^{7}$. The greater the exposure and the amount of associated factors, the more susceptible the child will be to presenting delays.

Motor delay has a direct impact on infant mobility; thus, it should be identified as early as possible ${ }^{2}$. The difficulty of coordination and control of voluntary movements characterizes motor delay and negatively influences all dimensions of development ${ }^{8}$. Children with severe delays can develop severe deficiencies, which in the long run can have repercussions on poverty and social exclusion ${ }^{6}$. It is, therefore, essential to recognize the infants who are most at risk of motor delays in order for them to be referred to specialized care that stimulates all their potentialities, minimizing the deficit and favoring future quality of life ${ }^{9}$.

The literature considers the interaction between biological aspects, environmental experiences, and the specific requirement of the complexity of the movement as facilitators or barriers to motor development ${ }^{2,10,11}$. Hospitalization, therefore, represents a risk factor for child development, not only because of the environment and the procedures performed in hospital, but also often because of lack of adequate stimulation ${ }^{7}$.

During most part of hospital stay, infants remained restricted to bed, with little space for free movement and experiencing passivity in an environment related to pain and suffering ${ }^{12}$. Studies report that the hospital environment can generate problems in the infant's systems of self-regulation, which directly reflects on the homeostatic systems and interfere in the cognitive and learning development, when associated with the reason for hospitalization ${ }^{12,13}$.

In this context, this study evaluated the motor performance of hospitalized infants from zero to 18 months of age, and related children's biological characteristics, socioeconomic profile, length of hospital stay, and physiotherapeutic assistance.

\section{METHODS}

This cross-sectional, prospective and observational study was approved by the Research Ethics Committee of Unisinos, São Leopoldo, Brazil, registry 15/162 (Supplementary Material), and was conducted in compliance with the provisions of Resolution 466/12 from the National Health Council.

A total of 32 infants hospitalized in the pediatric unit of a medium-complexity public hospital in a metropolitan region of southern Brazil were evaluated from November 2015 to March 2016. The inclusion criteria were corrected age from zero to 18 months, hospital admission longer than 1 day, and informed consent form signed by the child's guardian. Exclusion criteria included postnatal hospitalization, disorders of neurological origin, congenital orthopedic problems, vision and hearing deficits, and crying that prevented the evaluation.

Data collection was performed using a questionnaire and a motor assessment scale within 24 hours before discharge. The questionnaire was applied individually to each infant's guardian and aimed to collect information on birth, history of the disease, social history, and family and socioeconomic issues. The family's socioeconomic status was investigated by the Brazil Criteria of Economic Classification (BCEC), a standardized instrument based on the consumption and socioeconomic stratification in Brazil and on the Brazilian Family Budget Survey of the Brazilian Institute of Geography and Statistics. The BCEC provides scores for possession of material goods, educational level of the head of the household, and access to public services, and, according to the overall score, stratifies the average household income in different economic classes (A: BRL 20, 272.56; B: BRL 6,561.62; C: BRL 1,927.61; D-E: BRL 639.78) ${ }^{14}$.

The motor performance of each infant was evaluated by the Alberta Infant Motor Scale (AIMS), validated for the Brazilian population in 2011, in a study that assessed its validity of content, reliability, and discriminant capacity for term and preterm groups ${ }^{15}$. The AIMS is an easy to apply and of low cost instrument to observe child's gross motor skills and assess motor development and control of the antigravity musculature, with minimal stimulus from the evaluator. It consists of 58 items tested in the prone, supine, sitting and standing positions. Scores for the observed items are added and converted into percentile of motor development. Percentiles above 25 were classified as typical motor development; from 5 to 25, as suspected motor delay; and below 5 , as motor delay ${ }^{16}$.

Motor evaluation was performed individually, when the infant was stable and accompanied in the room of hospitalization, on a surface previously prepared to reduce impacts and that allowed free movement, with toys that produced sound, stimulating colors and forms that were easy to grab. It had an average duration of 20 minutes each, at a time that would not be detrimental for child's treatment.

After data collection, the data were grouped, summarized and schematically organized in the Statistical Package for the Social Sciences (SPSS), version 21.0. A simple logistic regression analysis was conducted to assess the main risk factors (sex, prematurity, birth weight, reason for hospitalization, first hospitalization, history of previous illness, attendance at daycare centers, presence of sibling, 
physiotherapy during hospitalization, and socioeconomic classification) for motor development delay (AIMS percentile). All infants with motor performance below the 25 percentile were included in the "at risk" group. Simple linear regression analysis was used to investigate the possible association between length of hospitalization and motor development. Significance was established at $p<0.05$.

\section{RESULTS}

The non-random sample comprised 32 infants of both sexes, with an age range from zero to 18 months and an average hospital stay of $4.94 \pm 2.39$ days (minimum 2, maximum 10). A total of 11 infants (34.4\%) were preterm and, of these, four $(12.5 \%)$ presented birth weight below $2,500 \mathrm{~g}$. None of the infants needed ventilatory support during hospitalization. Most of the families in the sample $(n=16)$ belonged to socioeconomic class $C$, equivalent to an average household income of BRL 1,927.61. The neonatal,

Table 1: General characterization of participants $(n=32)$.

\begin{tabular}{|c|c|}
\hline Variables & Sample \\
\hline \multicolumn{2}{|l|}{$\operatorname{Sex}(n, \%)$} \\
\hline Female & $16(50)$ \\
\hline Male & $16(50)$ \\
\hline $\begin{array}{l}\text { Age (months, M } \pm S D \text { ) } \\
\text { (min.-max.) }\end{array}$ & $\begin{array}{l}8.13 \pm 5.52 \\
(0-18)\end{array}$ \\
\hline $\begin{array}{l}\text { Gestational age (weeks, M } \pm S D \text { ) } \\
\text { (min.-max.) }\end{array}$ & $\begin{array}{r}38 \pm 2.24 \\
(32-41)\end{array}$ \\
\hline $\begin{array}{l}\text { Length at birth (cm, M } \pm S D \text { ) } \\
\text { (min.-max.) }\end{array}$ & $\begin{array}{c}48.03 \pm 3.67 \\
\quad(39-54)\end{array}$ \\
\hline $\begin{array}{l}\text { Birth weight }(\mathrm{g}, \mathrm{M} \pm \mathrm{SD}) \\
\text { (min.-max.) }\end{array}$ & $\begin{array}{l}3,204.3 \pm 777.1 \\
(1,245-4,730)\end{array}$ \\
\hline \multicolumn{2}{|l|}{ Preterm $(n, \%)$} \\
\hline Yes & $11(34.4)$ \\
\hline No & $21(65.6)$ \\
\hline \multicolumn{2}{|l|}{ Previous illness (n, \%) } \\
\hline Yes & $7(21.9)$ \\
\hline No & $25(78.1)$ \\
\hline \multicolumn{2}{|l|}{ Daycare attendance (n, \%) } \\
\hline Yes & $11(34.4)$ \\
\hline No & $21(65.6)$ \\
\hline \multicolumn{2}{|l|}{ Siblings (n, \%) } \\
\hline Yes & $16(50.0)$ \\
\hline No & $16(50.0)$ \\
\hline \multicolumn{2}{|l|}{$\operatorname{BCEC}(n, \%)$} \\
\hline Class B & $6(18.7)$ \\
\hline Class C & $16(50.0)$ \\
\hline Class D-E & $10(31.3)$ \\
\hline
\end{tabular}

Note: Results expressed by mean (M), standard deviation (SD), minimum (min.) and maximum (max.) values, and proportions (\%) of the sample. BCEC: Brazil Criteria of Economic Classification. Source: Designed by authors. environmental and sociodemographic characteristics of the sample are presented in Table 1.

Motor performance assessment conducted in the last 24 hours of hospitalization identified several infants $(53 \%$ of the sample, $n=17)$ with motor scores that suggest risks for adequate motor development (suspected motor delay: $n=13$, delayed motor development: $n=4$ ). Hospital admission related to infectious processes (urinary tract infection, bacterial meningitis and gastroenteritis) was the most prevalent factor, occurring in $40.6 \%(n=13)$ of the sample. Table 2 presents health and environmental characteristics related to hospital admission.

A linear regression was conducted to investigate whether hospitalization time was related to motor performance variation, revealed that length of hospitalization explained only $3.3 \%$ of this variation $[r 2=0.033, F=(1.31)=1.01, p<0.322]$ and significant correlations were not observed $(\beta=-0.181, p<0.322)$. Table 3 presents the univariate logistic regression related to the risk factors for delayed motor development in the present study. The results showed that the most unfavorable socioeconomic classification (mean household income of BRL 639.78 - class D-E) had increased higher risks (odds ratio of 5.77) of

Table 2: Motor performance and characteristics associated with hospitalization $(n=32)$.

\begin{tabular}{|c|c|}
\hline Variables & Sample \\
\hline $\begin{array}{l}\text { Length of hospital stay (days, M } \pm S D \text { ) } \\
\text { (min.- max.) }\end{array}$ & $\begin{array}{l}4.94 \pm 2.39 \\
(2-10)\end{array}$ \\
\hline \multicolumn{2}{|l|}{ Disorder $(n, \%)$} \\
\hline Infectious & $13(40.6)$ \\
\hline Respiratory & $10(31.3)$ \\
\hline Inflammatory & $8(25)$ \\
\hline Other & $1(3.1)$ \\
\hline \multicolumn{2}{|l|}{ First hospitalization (n, \%) } \\
\hline Yes & $27(84.4)$ \\
\hline No & $5(15.6)$ \\
\hline \multicolumn{2}{|l|}{ Physiotherapy (n, \%) } \\
\hline Yes & $8(25)$ \\
\hline No & $24(75)$ \\
\hline \multicolumn{2}{|l|}{ Motor development } \\
\hline 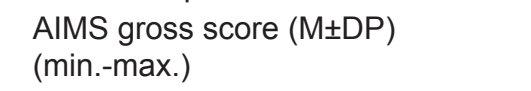 & $\begin{array}{l}29.44 \pm 20.34 \\
(3-58)\end{array}$ \\
\hline $\begin{array}{l}\text { AIMS percentile }(\mathrm{M} \pm \mathrm{DP}) \\
\text { (min.-max.) }\end{array}$ & $32.09 \pm 28.07$ \\
\hline AIMS categorization (n, \%) & $(0-97)$ \\
\hline Adequate & 15 (46.9) \\
\hline Suspected & $13(40.6)$ \\
\hline Delay & $4(12.5)$ \\
\hline $\begin{array}{l}\text { Note: Results expressed by mean (M), } \\
\text { (SD), minimum (min.) and maximum ( } \\
\text { proportion of participants (\%). AIMS: Alberta } \\
\text { Source: Designed by authors. }\end{array}$ & $\begin{array}{l}\text { ndard deviation } \\
\text { x.) values and } \\
\text { ant Motor Scale. }\end{array}$ \\
\hline
\end{tabular}


Table 3: Univariate logistic regression with possible risk factors for motor development alteration.

\begin{tabular}{|c|c|c|c|c|c|}
\hline & $\mathbf{n}$ & $\begin{array}{c}\text { Altered } \\
\text { n (\%) }\end{array}$ & $\begin{array}{c}\text { Normal } \\
\mathrm{n}(\%) \\
\end{array}$ & $\begin{array}{c}\text { OR } \\
(95 \% \mathrm{CI}) \\
\end{array}$ & p-value \\
\hline \multicolumn{6}{|l|}{ Sex } \\
\hline Male & 16 & $7(43.7)$ & $9(56.3)$ & 1.00 (ref) & \\
\hline Female & 16 & $10(62.5)$ & $6(37.5)$ & $2.14(0.52-8.8)$ & 0.24 \\
\hline \multicolumn{6}{|l|}{ Preterm } \\
\hline No & 21 & $9(42.9)$ & $12(57.1)$ & 1.00 (ref) & \\
\hline Yes & 11 & $8(72.7)$ & $3(27.3)$ & $3.55(0.73-17.3)$ & 0.11 \\
\hline \multicolumn{6}{|c|}{ Low birth weight } \\
\hline No & 27 & $13(48.1)$ & $14(51.9)$ & 1.00 (ref) & \\
\hline Yes & 5 & $4(80)$ & $1(20)$ & $4.30(0.42-43.7)$ & 0.21 \\
\hline \multicolumn{6}{|c|}{ Reason for Hospitalization } \\
\hline Respiratory & 11 & $4(36.4)$ & $7(63.6)$ & 1.00 (ref) & \\
\hline Infectious & 13 & $8(61.5)$ & $5(38.5)$ & $2.80(0.53-14.7)$ & 0.22 \\
\hline Inflammatory & 8 & $5(62.5)$ & $3(37.5)$ & $2.91(0.44-19.2)$ & 0.26 \\
\hline \multicolumn{6}{|c|}{ Previous hospitalizations } \\
\hline No & 27 & $14(51.9)$ & $13(48.1)$ & 1.00 (ref) & \\
\hline Yes & 5 & $3(60)$ & $2(40)$ & $1.39(0.20-9.71)$ & 0.73 \\
\hline \multicolumn{6}{|c|}{ Previous illness } \\
\hline No & 25 & $13(52.0)$ & $12(48.0)$ & 1.00 (ref) & \\
\hline Yes & 7 & $4(57.1)$ & $3(42.9)$ & $1.23(0.22-6.67)$ & 0.81 \\
\hline \multicolumn{6}{|c|}{ Daycare attendance } \\
\hline Yes & 11 & 2 (18.2) & $9(81.8)$ & 1.00 (ref) & \\
\hline No & 21 & $15(71.4)$ & $6(28.6)$ & $11.25(1.8-68.1)$ & 0.08 \\
\hline \multicolumn{6}{|l|}{ Siblings } \\
\hline Yes & 16 & $9(56.3)$ & $7(43.7)$ & 1.00 (ref) & \\
\hline No & 16 & $8(50)$ & $8(50)$ & $0.77(0.19-3.12)$ & 0.72 \\
\hline \multicolumn{6}{|c|}{ Performed physiotherapy } \\
\hline Yes & 8 & $2(25)$ & $6(75.0)$ & 1.00 (ref) & \\
\hline No & 24 & $15(62.5)$ & $9(37.5)$ & $5.00(0.82-30.2)$ & 0.08 \\
\hline \multicolumn{6}{|c|}{ Socioeconomic classification } \\
\hline Class B-C & 22 & $9(40.9)$ & $13(59.1)$ & 1.00 (ref) & \\
\hline Class D-E & 10 & $8(80)$ & $2(20)$ & $5.77(0.98-33.8)$ & 0.05 \\
\hline
\end{tabular}

95\% Cl: $95 \%$ confidence interval. OR: odds ratio. Source: Designed by authors.

showing inadequate motor development performance (delay/suspicion) when compared to the higher economic classes $(p=0.05)$.

\section{DISCUSSION}

The first 2 years of life are a critical period for development in its most varied aspects. The infant's growth and motor development do not depend only on the biological maturation provided by the central nervous system, but also on how the baby adapts to his/her physical conditions and environment, whether it is at home, daycare, or hospital ${ }^{8,17,18}$.

The study sample presented the same distribution between the sexes; however, ten girls $(62.5 \%)$ presented altered motor performance, being twice as likely to present delays when compared to males. In the infant population, however, the prevalence of delay in a given sex is not documented. Studies indicate that boys and girls have equivalent motor development during the first 2 years of life ${ }^{19,20}$. The differences between the sexes usually occur after the fourth year, when socialization and culturally reinforced play habits, they present differences in motor behavior ${ }^{4}$. It is believed that there are confounding factors for the result in this research, such as the overlapping of other known developmental risks, such as low birth weight, prematurity, previous hospitalizations, and low family income. Therefore, one plausible explanation is that the seven infants who were re-hospitalized were in majority girls. Also, it seems that the patients with higher prevalence of delays are the ones hospitalized for respiratory causes. The greater the number of 
risk factors, the greater the chances of the infant presenting delays $\mathbf{s}^{21,22}$.

The mean weight of the infants in this sample was $3,204.3 \pm 777.1 \mathrm{~g}$ at birth. Low birth weight is defined by the World Health Organization (WHO) as less than $2,500 \mathrm{~g}$ and in Brazil, the prevalence was $10 \%$ in the $2000 \mathrm{~s}^{23}$. In the present study, five infants were born with less than $2,500 \mathrm{~g}$, presenting four times more chances for alteration in motor development when compared to those in the sample with a higher weight, which corroborates the findings by Halpern et al. ${ }^{9}$, who, when evaluating children at 12 months, identified a reduction in risk of delay as there is an increase in birth weight. A literature review by Caçola and Bobbio $^{24}$ also states that low-birth-weight children are at increased risk for cognitive, motor, and behavioral developmental problems.

One of the factors that raises the chances of low birth weight is prematurity; however, not all preterm infants are born with less than 2,500g. Prematurity, as an isolated factor, is directly associated with morbidity related to infectious, neurological complications and with respiratory disorders ${ }^{22}$. In the present study, eight of the 11 preterm births $(72.7 \%)$ presented alterations in motor development (3.5 times greater chance), a risk also evidenced in the study by Santos et al. ${ }^{25}$ who found three times more chances of motor delay in preterm infants. However, Mancini et al. ${ }^{21}$ in a study that compared the function of preterm and term infants at 8 and at 12 months of age, concluded that, in the absence of other risk factors, the motor development of preterm infants may be similar to that of children born at term, when the age is corrected.

The present study was conducted in a hospital environment; therefore, it was hypothesized that hospitalizations of the preterm infants would be related to the premature birth and the associated biological risks factors. A history of health complications and re-hospitalization, after the premature birth, was reported for seven cases of the sample. Children who were re-hospitalized in the first year of life showed health complications during adverse climatic conditions (mostly fall and winter) associated with immaturity of organs and body systems, which are typical characteristics of preterm children. Immaturity of organs and body systems is recognized as a risk factor for adequate development whenever severe and constant exacerbations occur. The recurrence of unhealthy events may result in severe and/or prolonged hospitalizations, establishing risk condition for future cognitive deficits and behavioral and emotional disorders ${ }^{26,27}$. The increases in the odds ratios of infants with a history of hospitalization support the previous finding that girls who combined several risk factors were more frequently re-hospitalized and presented lower motor scores.

Restrictions in motor development are not necessarily related to neurological or structural disorders, since infants who do not have severe dysfunctions may have some degree of impairment in some developmental areas $^{2}$. In the present study, infants diagnosed with neurological restriction prior to admission were excluded from the sample; nonetheless, $53.1 \%$ $(n=17)$ of the children presented some sort of motor development delays (e.g. poor manipulation of objects; delays to achieve basic milestones). Previous studies highlighted that not only biological conditions, but also poor opportunities in the environment represent a hazard to motor development ${ }^{4,8,28,29}$. Limiting infants to use their movements to explore the environment and insufficient stimulation and toys to play are risk factors for the infant's appropriate development, but sometimes these factors are overlooked.

In the present study the identification of motor development delays in preterm infants could be associated with the presence of environmental risk factors (low income), as previously reported in the literature ${ }^{4,8}$. The average household income is a determining factor for the family' quality of life, since the difficulties associated with poverty reflect on the well-being of the parents and the interpersonal environment of the house ${ }^{30}$. In the present study, infants from lower income families (class D-E) were up to six times more likely to develop developmental alterations, as occurred in the results by Halpern et al. ${ }^{9}$, who verified the prevalence of suspected delay in the neuro-psychomotor development of 1-year-olds and, although not statistically significant when controlling for confounding factors, showed that children with lower family income were twice more likely to present suspected delays when compared to those with higher income. Therefore, a worse economic condition increases children's vulnerability, being a risk factor for their development.

It is not possible to understand the potential of stimulation of the family environment only from the average family income ${ }^{30}$. Studies report other family factors that may pose the risk for proper stimulation. Halpern et al. ${ }^{9}$ report that in families with higher numbers of children there is a worse quality of stimuli, probably associated with less caregiver availability. In the present study, not having siblings decreased the probability of developing developmental alterations by $23 \%$ when compared to those living with siblings at home. This finding is contrary to a previous study by Bueno et al. ${ }^{31}$, who studied the influence of the home environment on the motor development of infants and concluded that infants living in homes where there were no other infants had a higher prevalence 
of delays. The authors believe that this is because these infants have less opportunity to observe and reproduce activities that siblings already perform. Conversely, a cross-sectional study conducted by Andrade et al. ${ }^{10}$ with 350 children reports that the most adequate family stimulus was observed in families of children who do not live with other children under 5 years of age.

The daycare center, according to Brandley and Vandel ${ }^{32}$, is the main place where children perform the interaction of family and biological experiences. The small sample lacks statistical power to find significant differences, but infants who did not attend daycare centers were 11 times more likely to present with motor delay compared to those who attended these centers regularly, as also reported by Bueno et al. ${ }^{31}$, who observed better motor development in infants who attended daycare centers. Zajonz et al. ${ }^{29}$ in a motor intervention with 32 children between 6 and 18 months in different contexts, also suggest that daycare centers provide stimuli that are more prone to development.

Previous studies have questioned the quality of the daycare center as a development environment, and sustain that there is no direct effect on health promotion, especially when public and private daycare centers are compared ${ }^{31,33}$. In this study, the type of daycare center was not questioned, adopting the provisions of the National Curriculum Referential, which state that daycare education, whether private or public, has the purpose of creating conditions for the integral development of all children ${ }^{34}$.

The hospital environment is, in general, poorly adapted to child's needs of stimulation, with little possibilities of movement and interaction for the child. Some hospitals have playrooms in their facilities, which does not necessarily mean a correct interaction of the child with the environment, specifically regarding infants ${ }^{35}$. In the present study, no difference was observed in the motor development of infants who remained more or less time hospitalized, since length of hospital stay explained only $3.3 \%$ of variance in motor performance. A cross-sectional and comparative study with 12 infants conducted by Panceri et al. ${ }^{7}$ stated that in hospital admission of at least 30 days resulted in inadequate infant development when compared to the control group. Giachetta et al. ${ }^{13}$, when evaluating preterm newborns, reported that the longer the hospitalization time, the greater the motor impairment.

It is noteworthy that the maximum length of hospital stay in the sample was 10 days, possibly explaining the contrasting findings with the previously mentioned studies. Because it is a hospital of medium complexity, the degree of disease affection, symptomatology, and level of medical intervention are considered lower; otherwise, the baby is transferred to a hospital that provide high complexity pediatric care.

The highest demand for hospital care in the sample was due to infectious dysfunctions $(n=13)$ However, the infants who most presented motor impairment were those hospitalized due to inflammatory problems, who were almost three times more likely to present changes in development than the infectious group. The number of hospitalizations for infectious diseases is noteworthy, since many of these hospitalizations could have been avoided by primary health care ${ }^{36}$.

Primary care interventions can reduce the number of hospital admissions, mainly due to infectious and respiratory tract diseases that are avoidable through campaigns to promote health ant to prevent diseases and their aggravations and through diagnoses and treatment of acute episodes, which can reduce hospital admission ${ }^{37}$. Hospital admission generates stress on the child and exposure to other agents that cause illness, being an inhospitable environment with an invasive and stressful routine for the baby ${ }^{38}$. Even though the present study did not find any association between length of hospital stay and motor development, the period in the hospital may result in family and biological imbalances.

Physiotherapy has greater insertion in intensive care in pediatric hospitals, and its role in hospitalization units varies according to the child's health status ${ }^{39}$. In the present study, eight infants $(25 \%)$ underwent physiotherapy during hospitalization, all of which hospitalized with respiratory dysfunction, and presented five times less chance of altered motor development when compared to those who did not undergo physiotherapy. It is not possible to generalize this finding, since no infants received physiotherapeutic care when hospitalized for other reason, generating confusion about the type of care provided and the greater degree of motor impairment in infants undergoing physical therapy.

The recommendations for intervention and the pattern of physiotherapeutic procedures vary according to the place and the professional. There are institutions where the physician stipulates the indication of physiotherapy and others in which the physiotherapist evaluates all hospitalized patients. It is controversial to say that the professional's performance is related to the prediction of hospital discharge, but authors report that the physiotherapist's performance is related to lower complications, especially respiratory, which justifies the medical referral mainly to this type of impairment ${ }^{39,40}$. Formiga et al..$^{11}$ argue that physiotherapeutic interventions in the identified motor development problems present satisfactory results; however, many children are referred to the 
service late, which restricts treatment effectiveness, since it cannot prevent changes already installed.

Thus, in this study, days of hospitalization and hospital environment were not significant risk factors when analyzed individually. We concluded that the greater the exposure and the amount of associated factors, the more susceptible the child will be to present motor delays. Circumstantial motor delay after hospitalization and confounding factors linked to physiotherapy should be considered.

It is also necessary to insert physiotherapy monitoring in the other complications besides the respiratory ones, which are more commonly experienced in the hospital environment. The physiotherapist's challenge in this context is to identify the risk of delay, not only biological, but mainly environmental, and intervene at an early stage, performing adequate follow-up after hospital discharge, in order to minimize the onset of dysfunctions.

As limitations of this study, we can mention the fact that the number of family members was not questioned and physiotherapeutic assistance was identified only in respiratory dysfunctions. For future studies, it is suggested a longitudinal follow-up of a more representative sample in a high complexity hospital.

\section{Conflicts of Interest}

The authors declare no conflicts of interest.

\section{REFERENCES}

1. Lundy-Ekman L. Neurociência: fundamentos para a reabilitação. 2nd ed. Rio de Janeiro: Elsevier; 2004.

2. Willrich A, Azevedo CCF, Fernandes JO. Motor development in childhood: influence of the risk factors and intervention programs. Rev Neurocienc. 2009;17:51-6.

3. Resende JCS, Nunes KH, Roseira MC, Timóteo JM, Cagno MJS, Grecco MV. Idade motora de crianças e jovens do Programa de Atividades Comunitárias (PAC) da Universidade São Judas Tadeu. Rev Bras Fisiol Exerc. 2013;12:364-9.

4. Pereira KRG, Valentini NC, Saccani R. Brazilian infant motor and cognitive development: longitudinal influence of risk factors. Pediatr Int. 2016;58(12):1297-306.

5. Gallahue DL. Classifying movement skills: a case for multidimensional models. Rev. Educ. Fís. UEM. 2002;13:105-11.

6. World Health Organization (WHO). Early childhood development and disability: a discussion paper. Geneva: WHO; 2012. [cited 2017 Sep 5]. Available from: http://apps.who.int/iris/ bitstream/10665/75355/1/9789241504065 eng.pdf

7. Panceri C, Pereira KRG, Valentini NC, Sikilero RHAS. The influence of hospitalization on motor development of infants admitted to Hospital de Clínicas de Porto Alegre. Rev HCPA. 2012;32:161-8.
8. Saccani R, Valentini NC, Pereira KRG, Müller AB, Gabbard C. Associations of biological factors and affordances in the home with infant motor development. Ped Int. 2013;55:197203.

9. Halpern R, Giugliani ER, Victora CG, Barros FC, Horta BL. Risk factors for suspicion of developmental delays at 12 months of age. J Pediatr. 2000;76:421-8.

10. Andrade SA, Santos DN, Bastos AC, Pedromônico MRM, Almeida-Filho $\mathrm{N}$, Barreto ML. Family environment and child's cognitive development: an epidemiological approach. Rev Saude Publica. 2005;39:606-11.

11. Formiga CKMR, Pedrazzani ES, Tudella E. Desenvolvimento motor de lactentes pré-termo: fisioterapêutica precoce. Rev Bras Fisioter. 2004;8:239-45.

12. Oliveira GF, Dantas FDC, Fonseca PN. O impacto da hospitalização em crianças de 1 a 5 anos de idade. Rev SBPH. 2004;7:37-54.

13. Giachetta L, Nicolau CM, Costa APBM, Zuana AD. Influence of length of hospitalization on neuromotor development in premature newborn infants. Fisioter Pesqui. 2010;17:24-9.

14. Associação Brasileira de Empresas de Pesquisa (ABEP). Critério de Classificação Econômica Brasil (CCEB). São Paulo: ABEP; 2015. [cited 2017 Sep 5]. Available from: http://www.abep.org/criterio-brasil.
15. Valentini NC, Saccani R. Infant Motor Scale of Alberta: validation for a population of Southern Brazil. Rev Paul Pediatr. 2011;29:231-8.

16. Piper MC, Pinnell LE, Darrah J, Maguire T, Byrne PJ. Construction and validation of the Alberta Infant Motor Scale (AIMS). Can J Public Health. 1991;83:S46-50.

17. Bortolete GS, Brêtas JR. The stimulating environment for the development of hospitalized children. Rev Esc Enferm USP. 2008;42:422-9.

18. Dias VLM, Sant'Anna ET, Motta MGC, Ribeiro NRR. Ações de estimulação à criança na unidade de tratamento intensivo pediátrico. Rev Gaúcha Enferm. 1998;9:73-6.

19. Ferreira M, Böhme MTS. Diferenças sexuais no desempenho motor de crianças: Influência da adiposidade corporal. Rev Paul Educ Fís. 1998;12:181-92.

20. Venturella CB, Zanandrea G, Saccani $\mathrm{R}$, Valentini NC. Motor development of children between 0 and 18 months of age: differences between sexes. Motricidade. 2013;9:3-12.

21. Mancini MC, Teixeira $S$, Araújo LG, Paixão ML, Magalhães LC, Coelho ZAC, et al. Estudo do desenvolvimento da função motora aos 8 e 12 meses de idade em crianças nascidas pré-termo $\mathrm{e}$ a termo. Arq Neuropsiquiatr. 2002;60:974-80. 
22. Salge AKM, Vieira AVC, Aguiar AKA, Lobo SF, Xavier RM, Zatta LT, et al. Fatores maternos e neonatais associados à prematuridade. Rev Eletr Enf. 2009;11:642-6.

23. United Nations Children's Fund and World Health Organization (UNICEF). Low birthweight: country, regional and global estimates. New York: UNICEF; 2004.

24. Caçola P, Bobbio TG. Low birth weight and motor development outcomes: the current reality. Rev Paul Pediatr. 2010;28:70-6.

25. Santos DCC, Tolocka RE, Carvalho J, Heringer LRC, Almeida CM, Miquelote AF. Gross motor performance and its association with neonatal and familial factors and day care exposure among children up to three years old. Rev Bras Fisioter. 2009;13:173-9.

26. Linhares MBM, Carvalho AEV, Machado C, Martinez FE. Desenvolvimento de bebês nascidos pré-termo no primeiro ano de vida. Paidéia. 2003;13:59-72.

27. Saldanha CT, da Silva AM, Botelho C. Climate variations and health services use for the treatment of asthmatic children under five years of age: an ecological study. J Bras Pneumol. 2005;31:492-8.
28. Rosa F No, Santos APM, Xavier RFC, Amaro KN. Importance of motor assessment in school children: analysis of the reliability of the Motor Development Scale. Rev Bras Cineantropom Desempenho Hum. 2010;12:422-7.

29. Zajonz R, Müller AB, Valentini NC. A influência de fatores ambientais no desempenho motor e social de crianças da periferia de Porto Alegre. Rev. Educ. Fís. UEM. 2008;19:159-71.

30. Martins MFD, Costa JSD, Saforcada ET, Cunha MDC. Quality of the environment and associated factors: a pediatric study in Pelotas, Rio Grande do Sul, Brazil. Cad Saude Publica. 2004;20:710-8.

31. Bueno EA, Castro AAM, Chiquetti EMS. Motor development home environment influence of premature infants. Rev Neuroc. 2014;22:45-52.

32. Brandley RH, Vandell DL. Child care and the well-being of children. Arch Pediatr Adolesc Med. 2007;161:66976.

33. Moreira LVC, Lordelo ER. Creche em ambiente urbano pobre: ressonâncias no ecossistema desenvolvimental. Interação Psicol. 2002;6:19-30.
34. Brasil. Ministério da Educação e do Desporto. Secretaria de Educação. Referencial curricular nacional para educação infantil. Brasília: MEC/SEF; 1998.

35. Mitre RMA, Gomes R. The play promotion in the context of childhood hospitalization as a health procedure. Cien Saude Colet. 2004;9:147-54.

36. Homar JC, Starfield B, Ruiz ES, Pérez $\mathrm{EH}$, Mateo MM. La atencion primaria de salud y las hospitalizaciones por ambulatory care sensitive conditions en Cataluna. Rev Clin Esp. 2001;201:501-7.

37. Costa JSD, Büttenbender DC, Hoefel AL, Souza LL. Hospitalization for primary care sensitive conditions in municipalities with full local health management control in Rio Grande do Sul State, Brazil. Cad Saude Publica. 2010;26:358-64.

38. Lamego DTC, Deslances SF, Moreira MEL. Challenges for humanization of care in a surgical neonatal intensive care unit. Cien Saude Colet. 2005;10:669-75.

39. Pountnet T. Fisioterapia pediátrica. Rio de Janeiro: Elsevier; 2008.

40. Vansconcelos GAR, Almeida RCA, Bezerra AL. Repercussion of physiotherapy in the neonatal intensive care unit. Fisioter Mov. 2011;24:65-73. 